\title{
Day 3 Embryo Fragmentation Is Associated With Singleton Birthweight Following Fresh Single Blastocyst Transfer囚A Retrospective Study
}

jiali Cai

Xiamen University Affiliated Chenggong Hospital

Lanlan Liu

Xiamen University Affiliated Chenggong Hospital

Jinghua Chen

Xiamen University Affiliated Chenggong Hospital

Zhenfang Liu

Xiamen University Affiliated Chenggong Hospital

\section{Wenjie Wang}

Xiamen University Affiliated Chenggong Hospital

\section{Xiaoming Jiang}

Xiamen University Affiliated Chenggong Hospital

Haixiao Chen

Xiamen University Affiliated Chenggong Hospital

Jianzhi Ren ( $\nabla$ rjz174@126.com )

Affiliated Chenggong Hospital of Xiamen University

\section{Research Article}

Keywords: fragmentation, birthweight, large for gestational age, blastocyst, inner cell mass

Posted Date: November 22nd, 2021

DOI: https://doi.org/10.21203/rs.3.rs-1037997/v1

License: @) (1) This work is licensed under a Creative Commons Attribution 4.0 International License. Read Full License 


\section{Abstract \\ Background}

Previous studies arguably associated poor embryo morphology with low birthweight in singletons following single embryo transfer. However, the association between specific morphological features on the cleavage stage and birthweight is still less known. The purpose of the study was to investigate whether embryo morphological features at the cleavage stage affect birthweight following blastocyst transfer

\section{Methods}

The single-center, retrospective cohort study included 4226 singletons derived from fresh single cleavage stage embryo transfer (ET, $n=1185$ ), fresh single blastocyst transfer (BT, n=787), or frozen-thawed single blastocyst transfer (FBT, n=2254) between 2016 and 2019. The morphological parameters including early cleavage, day 3 fragmentation, symmetry, blastomere number, and blastocyst morphology were associated with neonatal birthweight and z-score in multivariate regression models. Models were adjusted for maternal age, BMI, parity, peak estradiol level, endometrial thickness, insemination protocol, female etiologies, order of transfer, mode of delivery, and year of treatment.

\section{Results}

Adjusted for confounders, fragmentation was the only morphology feature associated with birthweight and z-score, while early cleavage, symmetry, blastomere number and blastocyst morphology were not. Fragmentation increased the birthweight in both ET group (115.4g, $95 \%$ Cl: 26.6 to 204.2$)$ and BT group (168.8g, 95\% Cl: 48.8 to 288.8 ), but not in FBT group (7.47g, 95\% Cl: -46.4 to 61.3$)$. The associations of birthweight and morphological parameters were confirmed in analyses for z-score. Adjusted odds of large for gestational age and high birthweight were also significantly greater in singletons following the transfer of fragmented embryos in BT group (OR 3,95\% Cl: 1.2 to $7.51, \mathrm{OR} 3.65,95 \% \mathrm{Cl}$ : 1.33 to 10, respectively). The presence of fragmentation at the cleavage stage also affected the association between blastocyst morphology and birthweight. Inner cell mass grades were negatively associated with birthweight in blastocysts with day 3 fragmentation but not in blastocysts without.

\section{Conclusions}

Birthweight following blastocyst transfer is positively associated with fragmentation at the cleavage stage. The data did not support the argument that transferring a poor-looking embryo may increase the risks of low birthweight. However, concerns for LGA infants still remain.

\section{Background}

Despite a rapid evolution of technologies for embryo assessment has been occurred within the past decade, conventional embryo morphology assessment based on microscopic observation remains a routine procedure for many embryo laboratories and continues to play a key role in quality control systems(1). Morphology features observed within a fixed time period post-insemination, such as degree of fragmentation, rate of cell division, size of blastomeres and morphology of trophectoderm (TE) and inner cell mass (ICM) have been proposed as indicators for embryo quality and developmental potential(2). Embryos with one or more unfavorable morphology features are believed to be of poorer quality and less likely to result in a live birth.

With a lower chance, however, achieving a live birth is still possible following transferring embryos with poor morphology. It raised the question whether the children derived from poor-looking embryos differ from those with "standard" morphology at their early stage of life. Several investigators have evaluated the association between embryo quality according to morphology and neonatal outcomes, showing that transferring poor quality embryo at either cleavage or blastocyst stage is associated with low birthweight in offspring $(3,4)$. It suggests a potential link between embryo morphology and fetal development. However, their results conflict with other studies(5-7) demonstrating a lack of association between embryo morphology and birthweight and are hampered by the subjectivity of the criteria. Other authors have associated birthweight with specific morphological parameters, such as day 3 cell number, advanced ICM grades and TE morphology(8-11). These data suggest that specific parameters rather than overall embryo grading might have an impact on birthweight. However, whether or how these morphological parameters interact or work in combination with each other is not yet clear.

Recently, data suggested that unfavorable morphological features at the cleavage stage may impair implantation and live birth following blastocyst transfer, even high quality blastocysts were transferred(12-14). Such studies highlighted the need to combine the evaluation of cleavage stage and blastocyst morphology to assess the developmental potential of a blastocyst. We hypothesize that the combination of cleavage stage and blastocyst morphology may also link to variation of birthweight following IVF, even the morphological grades of transferred blastocysts were similar. The aim of present study was to evaluate the association between day 3 morphology features and birthweight in both cleavage stage and blastocyst transfer and to examine whether day 3 morphology modifies the association between birthweight and blastocyst morphology.

\section{Methods}

\section{Study subjects}

Institutional Review Board approval for this retrospective study was obtained from the Ethical Committee of the Medical College Xiamen University. 
All patients who underwent single embryo transfer in either fresh or frozen-thawed cycles in the affiliated Chenggong Hospital of Xiamen University in the period between January 2016 and December 2019 were accessed for potential inclusion. Only cycles resulting in singleton live birth were included. Exclusion criteria were vanishing twin, very preterm birth (gestational week $<26$ ), patients reporting maternal gestational hypertension or diabetes, uterine abnormalities and unknown perinatal outcomes due to incomplete record. To minimize the maternal confounding, we also excluded maternal metabolism-related conditions, including PCOS and glucose intolerance. Female smokers were excluded from the study rather than be considered as a confounder because of the small number of the event $(n=28)$. The present study did not analyze the embryo with early compaction on day 3 , because our grading system did not record the cell number or fragmentation if early compaction occurred. A previous study suggested that the effects of early compaction may be modified by other morphological parameters(15).

Laboratory procedures and embryo assessment

Patients received ovarian stimulation as previously described(16). Following OPU, oocytes were inseminated using either conventional IVF or ICSI, with fertilization results checked 18-20 hours following insemination. Embryos and blastocysts were all cultured in single droplets since insemination was done. All oocytes and embryos were cultured in Cook series media (KSIFM, KSICM or KSIBM, COOK MEDICAL, Bloomington, IN) with oil overlay (OVOIL, Vitrolife, Göteborg, Sweden) in traditional incubators (C200, Labotect, Göttingen, Germany) at $37^{\circ} \mathrm{C}, 6 \% \mathrm{CO}_{2}, 5 \% \mathrm{O}_{2}$.

For cleavage stage embryos, embryo quality was assessed with a combination of cell number, blastomere size and degree of fragmentation. Grade I embryos (good quality) were defined as 8 cell embryos with evenly sized blastomeres and no more than $5 \%$ fragmentation. Grade II embryos (fair quality) were 7-10 cell embryos with minor defects in blastomere size or moderate fragmentation (10\%-15\%). Grade III embryos (poor quality) were embryos with two of the following defects: cell number $<7$ or $>10$; abnormally sized blastomeres and fragmentation rate $\geqq 10 \%$. Embryos with severe fragmentation ( $\geqq 50 \%$ ) and embryos with a combination of more than two major defects were not considered for transfer.

For blastocysts, Gardner grading system(1) was utilized for assessment. The degree of expansion (1: the blastoele is $<50 \%$ volume of the embryo; 2 : the blastoele is $\geqq 50 \%$ volume of the embryo; 3 : the blastocoel fills the whole embryo; 4 : the blastocoel volume is increased with zona thinning; 5 : the TE partially escapes from the zone; 6 : the blastocyst completely hatches from the zona), the morphology of inner cell mass (A: many cells, tightly packed; B: fewer cells, loosely packed; C: very few cells) and the morphology of TE (A: a cohesive epithelium with many cells, typically $>12$ cells at the equator of the blastocyst; $B$ : a loose epithelium with fewer cells, typically $7-12$ cells at the equator of the blastocyst; C: very few large, irregularly sized cells, typically $<7$ cells at the equator of the blastocyst) were evaluated accordingly. Blastocyst with poor morphological score ( $\leq \mathrm{CC}$ ) or low expansion grade (grades 1-2) were not considered for cryopreservation or transfer. To facilitate comparing our results with others, quality categories similar to a previous study(4) was used in the present study: top quality, $A A$; good quality, $\mathrm{AB}$ and $\mathrm{BA}$; average quality, $\mathrm{AC}, \mathrm{CA}$ and $\mathrm{BB}$; and poor quality, $\mathrm{BC}$ and $\mathrm{CB}$.

For cryopreservation of the embryo, a vitrification protocol, employing $15 \%$ dimethyl sulfoxide, $15 \%$ ethylene glycol, and $0.6 \mathrm{M}$ sucrose as cryoprotectants, was used. Blastocoelic volume was reduced before cryopreservation using a laser system (SATURN, RI, Falmouth, UK).

Embryo transfers were performed by using a Cook catheter (K-JETS-7019-SIVF, Cook, IN, USA) under the guidance of abdominal ultrasonography. Assisted hatching was not performed during the period of study. Luteal support continued until 10 weeks of pregnancy.

Statistics

The main outcomes measured were absolute birthweight and birthweight z-score adjusted for gestational age and gender. Z-score was calculated as the weight of the individual child minus the media weight of a reference population of children born at the same gestational age and of the same gender divided by the standard deviation from the same reference population. We used a birthweight reference for Chinese population generated by National Populationbased Birth Defects Surveillance System for calculation(17). The calculation of small-for-gestational-age (SGA) and large-for-gestational-age (LGA) also used the same reference. LGA was defined as newborns with a birth weight $>90$ th percentile for that gestational age and gender. SGA was defined as newborns with a birth weight $<10$ th percentile for that gestational age and gender.

Association between embryo morphological parameters and birthweight outcomes was analyzed using generalized linear models (GLM). Models were adjusted for a set of covariates which may affect the birthweight outcomes following embryo transfer, including maternal age, BMI, parity, peak estradiol level and endometrial thickness. Potential confounders, including insemination protocol (IVF or ICSI), female etiologies (tubal factor, endometriosis), order of transfer (1 or >1), mode of delivery (vaginal or cesarean) and year of treatment were also included. To analyze the absolute birthweight, models were also adjusted for gestational age and gender. The same set of covariates was also used in multivariate analyses for LGA, SGA, high birthweight (>4000g, HBW) and low birthweight $(<2500 \mathrm{~g}$, LBW).

Morphological parameters evaluated were early cleavage on day 1 (yes or not), fragmentation ( $<10 \%$ or $\geqq 10 \%)$, cell number ( $<8$ cells, 8 cells or $>8$ cells) and symmetry (even or uneven) on day 3 and ICM/TE (grade A, B or C) morphology on day 5 . We used two methods to evaluate the combinational effects of cleavage stage and blastocyst morphology on birthweight. First, the morphological parameters were assumed to be independent and served as confounders to each other in the multivariate models. Second, interactions between morphological parameters were introduced into the multivariate models. To simplify the interpretation of the data, only two-way interactions were considered. The patterns of postulated interactions were first checked in a main-effect only model then confirmed in a multivariate model.

All calculations were performed with SPSS (version 19; IBM).

\section{Results}


A total of 5228 singleton live births following single embryo transfer was reviewed for potential inclusion. After excluding incomplete records ( $\mathrm{n}=\mathbf{2 0}$ ), very preterm births $(n=20)$, vanishing twin $(n=27)$, reported gestational diabetes $(n=26)$ and hypertension $(n=59)$ cases, uterine abnormalities $(n=28)$, glucose intolerance or diagnosed diabetes $(n=21)$, PCOS $(n=470)$, female smokers $(n=28)$ and early compaction $(n=176), 4353$ singletons were included. Among them, 1185 singletons were following fresh cleavage stage transfer, 127 singletons were following frozen-thawed cleavage stage transfer, 787 singletons were following fresh blastocyst transfer and 2254 singletons were following frozen-thawed blastocyst transfer. Due to the limited sample size, we did not further analyze singletons following frozen-thawed cleavage stage transfer, characteristics, outcomes and multivariate analyses for these patients were detailed in the supplementary data (supplementary Table S1 and S2).

For singletons following fresh cleavage stage transfers (ET), fresh blastocyst transfers (BT) and frozen-thawed blastocyst transfers (FBT), patient characteristics, embryo parameter distribution and neonatal outcomes were provided in Table 1. The median [IQR] of maternal age and BMI of the overall population was 30 [28 to 33] and 20.9 [19.4 to 22.5], respectively. The median birthweight, z-score and gestational age of singletons was 3250 [3000 to 3500 ] g, $-0.11[-0.74$ to 0.55$]$ and 39 [38 to 40$]$ weeks, respectively. 
Table 1

Patients characteristics and neonatal outcomes

\begin{tabular}{|c|c|c|c|c|}
\hline \multicolumn{2}{|l|}{ Variable } & Fresh cleavage & Fresh blastocyst & Frozen blastocyst \\
\hline \multicolumn{2}{|l|}{$\mathrm{N}$} & 1185 & 787 & 2254 \\
\hline \multicolumn{2}{|l|}{ Maternal age, year } & 31 [28-34] & 31 [28-33] & 30 [27-32] \\
\hline \multicolumn{2}{|c|}{ Maternal BMI, kg/cm2 } & $21.2[19.6-22.7]$ & 21.3 [19.7-22.685] & $20.7[19.1-22.3]$ \\
\hline \multirow[t]{2}{*}{ Maternal etiology } & Tubal & $137(11.6)$ & $88(11.2)$ & $204(9.1)$ \\
\hline & Endometriosis & $760(64.1)$ & $524(66.6)$ & $1495(66.3)$ \\
\hline \multirow[t]{2}{*}{ Insemination } & IVF & $858(72.4)$ & $587(74.6)$ & $1634(72.5)$ \\
\hline & ICSI & $327(27.6)$ & $200(25.4)$ & $620(27.5)$ \\
\hline \multirow[t]{2}{*}{ ET order } & 1 & $193(16.3)$ & $222(28.2)$ & $320(14.2)$ \\
\hline & $>1$ & $992(83.7)$ & $565(71.8)$ & 1934 (85.8) \\
\hline \multirow[t]{2}{*}{ Parity } & 0 & $827(69.8)$ & $568(72.2)$ & $1922(85.3)$ \\
\hline & $\geqq 1$ & $358(30.2)$ & $219(27.8)$ & $332(14.7)$ \\
\hline \multicolumn{2}{|c|}{ Endometrial thickness, $\mathrm{mm}$} & $10.8[9.4-12.6]$ & $11[9.4-12.7]$ & $8.8[7.8-10.1]$ \\
\hline \multicolumn{2}{|c|}{ Peak estradiol level, pg/L } & 2196.5 [1128.25-3788.75] & 3597 [2305-4552] & 291 [208-398] \\
\hline \multirow[t]{4}{*}{ Year of treatment } & 2016 & $117(9.9)$ & $92(11.7)$ & $158(7)$ \\
\hline & 2017 & $336(28.4)$ & $100(12.7)$ & $432(19.2)$ \\
\hline & 2018 & $320(27)$ & $166(21.1)$ & $566(25.1)$ \\
\hline & 2019 & $412(34.8)$ & $429(54.5)$ & $1098(48.7)$ \\
\hline \multicolumn{5}{|l|}{ Embryo features } \\
\hline \multicolumn{2}{|l|}{ Early cleavage } & $834(70.4)$ & $577(73.3)$ & $1477(65.5)$ \\
\hline \multicolumn{2}{|c|}{ Day 3 fragmentation $\geqq 10 \%$} & $85(7.2)$ & $48(6.1)$ & $241(10.7)$ \\
\hline \multirow[t]{3}{*}{ Day 3 cleavage } & 8 cells & $937(79.1)$ & $532(67.6)$ & $1200(53.2)$ \\
\hline & $<8$ cells & $135(11.4)$ & $88(11.2)$ & $501(22.2)$ \\
\hline & $>8$ cells & $113(9.5)$ & $167(21.2)$ & $551(24.4)$ \\
\hline \multicolumn{2}{|l|}{ Day 3 asymmetry } & $160(13.5)$ & $120(15.2)$ & $493(21.9)$ \\
\hline \multirow[t]{3}{*}{ Blastocyst ICM } & A & - & $126(16)$ & $488(21.7)$ \\
\hline & B & - & $649(82.5)$ & $1727(76.6)$ \\
\hline & $\mathrm{C}$ & - & $12(1.5)$ & $39(1.7)$ \\
\hline \multirow[t]{3}{*}{ Blastocyst TE } & $A$ & - & $292(37.1)$ & $864(38.3)$ \\
\hline & B & - & $479(60.9)$ & $1320(58.6)$ \\
\hline & C & - & $16(2)$ & $70(3.1)$ \\
\hline \multirow[t]{3}{*}{ Cleavage score } & Grade III & $91(7.7)$ & $93(11.8)$ & $476(21.1)$ \\
\hline & Grade II & $983(83)$ & $661(84)$ & $1696(75.2)$ \\
\hline & Grade I & $111(9.4)$ & $33(4.2)$ & $80(3.5)$ \\
\hline \multirow[t]{4}{*}{ Blastocyst score } & Top & & $86(10.9)$ & $327(14.5)$ \\
\hline & Good & & $246(31.3)$ & 697 (30.9) \\
\hline & Fair & & $427(54.3)$ & $1122(49.8)$ \\
\hline & Poor & & $28(3.6)$ & $108(4.8)$ \\
\hline \multicolumn{5}{|l|}{ Neonatal outcomes } \\
\hline \multirow[t]{2}{*}{ Mode of delivery } & Vaginal & $493(41.6)$ & $339(43.1)$ & $889(39.4)$ \\
\hline & Cesarean & $692(58.4)$ & $448(56.9)$ & $1365(60.6)$ \\
\hline Offspring gender & Female & $557(47)$ & $346(44)$ & $965(42.8)$ \\
\hline
\end{tabular}

Page 5/12 


\begin{tabular}{|c|c|c|c|}
\hline Variable & Fresh cleavage & Fresh blastocyst & Frozen blastocyst \\
\hline Male & $628(53)$ & $441(56)$ & 1289 (57.2) \\
\hline Birthweight, g & 3200 [2900-3500] & 3200 [2920-3500] & 3250 [3000-3550] \\
\hline Z-score & $-0.22[-0.8$ to 0.42$]$ & $-0.22[-0.8$ to 0.54$]$ & $-0.06[-0.63$ to 0.65$]$ \\
\hline Gestational age, week & 39 [38-40] & $39[38-40]$ & $39[38-40]$ \\
\hline Preterm birth & $59(5)$ & $43(5.5)$ & $120(5.3)$ \\
\hline LBW, <2500g & $69(5.8)$ & $54(6.9)$ & $129(5.7)$ \\
\hline $\mathrm{HBW},>4000 \mathrm{~g}$ & $65(5.5)$ & $42(5.3)$ & $139(6.2)$ \\
\hline LGA & $105(8.9)$ & $64(8.1)$ & $216(9.6)$ \\
\hline SGA & $148(12.5)$ & 99 (12.6) & $196(8.7)$ \\
\hline
\end{tabular}

The associations between z-score and morphology features of transferred embryos were given in Table 2. Among morphology features evaluated in the present study, embryo fragmentation was the only one which is associated with the z-score of singletons following transfer. In both ET cycles and BT cycles, singleton birthweight z-score following transfer of fragmented embryos ( $\geqq 10 \%)$ on day 3 was significantly higher than that after transfer of embryos with no or little fragmentation ( 0.17 versus -0.15 for cleavage, 0.22 versus -0.13 for blastocyst). In FBT cycles, however, fragmentation on day 3 appeared to have no impact on $\mathrm{z}$-score $(0.06$ versus 0.02$)$. Adjusted for aforementioned covariates, the association between fragmentation and z-score remained significant in ET and BT cycles (Table 2). 
Table 2

Association between embryo morphological features and z-score

\begin{tabular}{|c|c|c|c|c|c|c|c|c|c|c|}
\hline \multirow[t]{3}{*}{ Variable } & \multirow[t]{3}{*}{ category } & \multicolumn{4}{|c|}{ Fresh cleavage transfer } & \multicolumn{4}{|c|}{ Fresh blastocyst transfer } & \multirow{3}{*}{$\begin{array}{l}\text { Fro } \\
\text { una } \\
\text { coe }\end{array}$} \\
\hline & & \multicolumn{2}{|l|}{ unadjusted } & \multicolumn{2}{|l|}{ adjusted } & \multicolumn{2}{|l|}{ unadjusted } & \multicolumn{2}{|l|}{ adjusted } & \\
\hline & & coefficient $(95 \% \mathrm{Cl})$ & $\mathrm{P}$ & coefficient $(95 \% \mathrm{Cl})$ & $\mathrm{P}$ & coefficient $(95 \% \mathrm{Cl})$ & $\mathrm{P}$ & coefficient( $(95 \% \mathrm{Cl})$ & $\mathrm{P}$ & \\
\hline \multirow[t]{2}{*}{ Early cleavage } & yes & $\begin{array}{l}-0.01(-0.14 \text { to } \\
0.13)\end{array}$ & 0.907 & $\begin{array}{l}-0.01(-0.14 \text { to } \\
0.12)\end{array}$ & 0.909 & $\begin{array}{l}0.12(-0.05 \text { to } \\
0.29)\end{array}$ & 0.163 & $\begin{array}{l}0.11(-0.07 \text { to } \\
0.28)\end{array}$ & 0.231 & $\begin{array}{l}0.0 \\
0.1\end{array}$ \\
\hline & no & Ref & - & Ref & - & Ref & - & Ref & - & Ref \\
\hline \multirow[t]{2}{*}{ Fragmentation } & $\geqq 10 \%$ & $\begin{array}{l}0.33(0.09 \text { to } \\
0.56)\end{array}$ & 0.006 & $0.27(0.03$ to 0.5$)$ & 0.024 & $\begin{array}{l}0.35(0.04 \text { to } \\
0.66)\end{array}$ & 0.029 & $\begin{array}{l}0.42(0.11 \text { to } \\
0.74)\end{array}$ & 0.009 & 0.0 \\
\hline & $<10 \%$ & Ref & - & Ref & - & Ref & - & Ref & - & Ref \\
\hline \multirow[t]{3}{*}{ Cell number } & $>8$ cells & $\begin{array}{l}0.18(-0.03 \text { to } \\
0.38)\end{array}$ & 0.097 & $\begin{array}{l}0.15(-0.06 \text { to } \\
0.36)\end{array}$ & 0.16 & $0(-0.19$ to 0.19$)$ & 0.985 & $\begin{array}{l}-0.04(-0.23 \text { to } \\
0.16)\end{array}$ & 0.712 & $\begin{array}{l}0.0^{\prime} \\
0.1^{\prime}\end{array}$ \\
\hline & $<8$ cells & $\begin{array}{l}0.08(-0.11 \text { to } \\
0.27)\end{array}$ & 0.397 & $\begin{array}{l}-0.05(-0.25 \text { to } \\
0.15)\end{array}$ & 0.599 & $0.04(-0.2$ to 0.28$)$ & 0.744 & $\begin{array}{l}0.12(-0.12 \text { to } \\
0.36)\end{array}$ & 0.324 & 0.1 \\
\hline & 8 cells & Ref & - & Ref & - & Ref & - & Ref & - & Ref \\
\hline \multirow[t]{2}{*}{ Symmetry } & uneven & $\begin{array}{l}-0.01(-0.18 \text { to } \\
0.17)\end{array}$ & 0.95 & $\begin{array}{l}-0.09(-0.27 \text { to } \\
0.09)\end{array}$ & 0.327 & $\begin{array}{l}0.02(-0.19 \text { to } \\
0.23)\end{array}$ & 0.844 & $\begin{array}{l}0.04(-0.18 \text { to } \\
0.26)\end{array}$ & 0.708 & $\begin{array}{l}0.0^{\prime} \\
0.1^{\prime}\end{array}$ \\
\hline & even & Ref & - & Ref & - & Ref & - & Ref & - & Ref \\
\hline \multirow[t]{3}{*}{$\begin{array}{l}\text { Cleavage } \\
\text { score }\end{array}$} & Grade I & $\begin{array}{l}-0.15(-0.44 \text { to } \\
0.15)\end{array}$ & 0.321 & $0(-0.3$ to 0.3$)$ & 0.987 & $\begin{array}{l}-0.13(-0.56 \text { to } \\
0.29)\end{array}$ & 0.536 & $\begin{array}{l}-0.12(-0.54 \text { to } \\
0.3)\end{array}$ & 0.585 & $\begin{array}{l}-0.1 \\
0.0\end{array}$ \\
\hline & Grade II & $\begin{array}{l}-0.08(-0.31 \text { to } \\
0.15)\end{array}$ & 0.474 & $\begin{array}{l}0.05(-0.18 \text { to } \\
0.27)\end{array}$ & 0.702 & $\begin{array}{l}-0.17(-0.4 \text { to } \\
0.07)\end{array}$ & 0.159 & $\begin{array}{l}-0.14(-0.37 \text { to } \\
0.09)\end{array}$ & 0.24 & $\begin{array}{l}-0 . C \\
0.0\end{array}$ \\
\hline & Grade III & Ref & - & Ref & - & Ref & - & Ref & - & Ref \\
\hline \multirow[t]{3}{*}{ ICM } & $\mathrm{C}$ & - & - & - & - & $\begin{array}{l}0.25(-0.38 \text { to } \\
0.89)\end{array}$ & 0.434 & $\begin{array}{l}0.16(-0.49 \text { to } \\
0.81)\end{array}$ & 0.632 & $\begin{array}{l}0.2 \\
0.5\end{array}$ \\
\hline & B & - & - & - & - & $\begin{array}{l}-0.07(-0.28 \text { to } \\
0.13)\end{array}$ & 0.477 & $\begin{array}{l}-0.1(-0.33 \text { to } \\
0.13)\end{array}$ & 0.393 & $\begin{array}{l}0.0 \\
0.1\end{array}$ \\
\hline & A & - & - & - & - & Ref & - & Ref & - & Ref \\
\hline \multirow[t]{3}{*}{ TE } & C & - & - & - & - & $0.1(-0.44$ to 0.64$)$ & 0.711 & $\begin{array}{l}0.01(-0.54 \text { to } \\
0.57)\end{array}$ & 0.959 & $\begin{array}{l}0.1 \\
0.4\end{array}$ \\
\hline & B & - & - & - & - & $\begin{array}{l}-0.07(-0.23 \text { to } \\
0.09)\end{array}$ & 0.385 & $\begin{array}{l}-0.03(-0.2 \text { to } \\
0.13)\end{array}$ & 0.718 & $\begin{array}{l}-0 . C \\
0.0\end{array}$ \\
\hline & A & - & - & - & - & Ref & - & Ref & - & Ref \\
\hline \multirow[t]{4}{*}{$\begin{array}{l}\text { Blastocyst } \\
\text { score }\end{array}$} & Poor & - & - & - & - & $0.15(-0.31$ to 0.6$)$ & 0.534 & $\begin{array}{l}0.16(-0.31 \text { to } \\
0.62)\end{array}$ & 0.511 & $\begin{array}{l}0.2 \\
0.4\end{array}$ \\
\hline & Fair & - & - & - & - & $\begin{array}{l}-0.11(-0.36 \text { to } \\
0.14)\end{array}$ & 0.369 & $\begin{array}{l}-0.09(-0.36 \text { to } \\
0.17)\end{array}$ & 0.491 & $\begin{array}{l}0.0 \\
0.1\end{array}$ \\
\hline & Good & - & - & - & - & $\begin{array}{l}-0.04(-0.3 \text { to } \\
0.22)\end{array}$ & 0.761 & $\begin{array}{l}-0.03(-0.29 \text { to } \\
0.24)\end{array}$ & 0.853 & $\begin{array}{l}0.1 \\
0.2\end{array}$ \\
\hline & Top & - & - & - & - & Ref & - & Ref & - & Ref \\
\hline
\end{tabular}

Models were adjusted for maternal age, BMI, parity, peak estradiol level, endometrial thickness, insemination protocol (IVF or ICSI), female etiologies (tubal fa of delivery (vaginal or cesarean) and year of treatment

We also evaluated the associations between z-score and embryo/blastocyst quality (Table 2). Data showed no significant association between z-score and embryo/blastocyst grades regardless the type of transfer, except an increased in z-score was noted when poor quality blastocysts were transferred in FBT cycles. However, the association between z-score and blastocyst quality was no longer significant following adjustment for confounders.

The associations of z-score and morphological parameters were also confirmed in analyses for absolute birthweight (supplementary Table S3). Multivariate analyses suggested that transferring a fragmented embryo may lead to a 115.4 (95\% Cl: 26.6 to 204.2$) \mathrm{g}$ increase in birthweight following fresh cleavage transfer and a 168.8 (95\% Cl: 48.8 to 288.8$) \mathrm{g}$ increase following fresh blastocyst transfer.

We used interaction analyses to evaluate the effects of FET on the association between morphology and birthweight. The size of association of fragmentation with birthweight and z-score in FET group was decreased by 142.36 (95\% Cl: 15.86 to 268.87 ) and 0.34 (95\%Cl: 0.01 to 0.66$)$ respectively, in comparison with BT group. 
To examine whether birthweight increase with severity of fragmentation, we further categorized the degree of fragmentation into four groups (no fragmentation; low fragmentation, $<10 \%$; moderate fragmentation, $10-14 \%$; high fragmentation, $\geqq 15 \%$ ). In fresh transfer cycles, multivariate analyses suggested that in comparison with no fragmentation group, the low fragmentation, moderate fragmentation and high fragmentation group increased the birthweight by 2.04 ( $95 \% \mathrm{Cl}:-59.28$ to 63.36$) \mathrm{g}, 114.7$ (95\% Cl: 36.38 to 193.1$) \mathrm{g}$ and 214.8 (95\%: 62.54 to 367.08$)$ g, respectively. A similar trend was also observed for z-score (Figure S1), suggesting a dose-dependent effect of fragmentation on birthweight. On the other hand, no dose-dependent effect of fragmentation was detected in frozen-thawed cycles.

Since fragmentation has been associated with standardized and absolute birthweight, we also evaluate its association with other neonatal outcomes, including SGA, LGA, LBW, HBW and preterm birth (Table 3). The rates of LGA appeared to be increased following transfer of fragmented embryos (14.1\% versus $8.5 \%, p=0.077$ for fresh cleavage; $16.7 \%$ versus $7.6 \%, p=0.026$ for fresh blastocyst) and same was also observed for $\mathrm{HBW}(10.6 \%$ versus $5.1 \%, p=0.03$ for fresh cleavage; $14.6 \%$ versus $4.7 \%, p=0.003$ for fresh blastocyst). Multivariate analyses suggested that there was an approximately 2 -fold increase in the odds of LGA/HBW with fragmentation in fresh blastocyst transfer cycles.

Table 3

Association between fragmentation and neonatal outcomes

\begin{tabular}{|c|c|c|c|c|c|c|c|c|c|c|}
\hline & LBW & & HBW & & LGA & & SGA & & Preterm birth & \\
\hline & OR $(95 \% \mathrm{Cl})$ & $P$ & OR $(95 \% \mathrm{Cl})$ & $P$ & OR $(95 \% \mathrm{Cl})$ & $\mathrm{P}$ & OR $(95 \% \mathrm{Cl})$ & $\mathrm{P}$ & OR (95\% Cl) & $P$ \\
\hline Fresh cleavage & $\begin{array}{l}0.81 \text { ( } 0.28 \text { to } \\
2.36)\end{array}$ & 0.698 & $\begin{array}{l}1.91 \text { ( } 0.86 \text { to } \\
4.24)\end{array}$ & 0.114 & $\begin{array}{l}1.59(0.79 \text { to } \\
3.18)\end{array}$ & 0.193 & $\begin{array}{l}0.69 \text { (0.31 to } \\
1.51)\end{array}$ & 0.352 & $\begin{array}{l}0.5(0.12 \text { to } \\
2.14)\end{array}$ & 0.348 \\
\hline Fresh blastocyst & $\begin{array}{l}0.39 \text { ( } 0.08 \text { to } \\
2.06)\end{array}$ & 0.27 & $\begin{array}{l}3.65(1.33 \text { to } \\
10)\end{array}$ & 0.012 & 3 (1.2 to 7.51$)$ & 0.019 & $\mathrm{~N} / \mathrm{A}^{\mathrm{a}}$ & - & $\begin{array}{l}0.54(0.09 \text { to } \\
3.07)\end{array}$ & 0.484 \\
\hline $\begin{array}{l}\text { Fresh cleavage } \\
\text { +blastocyst }\end{array}$ & $\begin{array}{l}0.64(0.27 \text { to } \\
1.53)\end{array}$ & 0.312 & $\begin{array}{l}2.49 \text { ( } 1.36 \text { to } \\
4.55)\end{array}$ & 0.003 & $\begin{array}{l}1.99 \text { (1.17 to } \\
3.41)\end{array}$ & 0.012 & $\begin{array}{l}0.38(0.18 \text { to } \\
0.8)\end{array}$ & 0.011 & $\begin{array}{l}0.53 \text { ( } 0.19 \text { to } \\
1.51)\end{array}$ & 0.236 \\
\hline Frozen blastocyst & $\begin{array}{l}0.98(0.5 \text { to } \\
1.89)\end{array}$ & 0.943 & $\begin{array}{l}1.05(0.59 \text { to } \\
1.87)\end{array}$ & 0.861 & $\begin{array}{l}1.01(0.63 \text { to } \\
1.62)\end{array}$ & 0.97 & $\begin{array}{l}1.1(0.68 \text { to } \\
1.79)\end{array}$ & 0.694 & $\begin{array}{l}1.17(0.62 \text { to } \\
2.22)\end{array}$ & 0.629 \\
\hline
\end{tabular}

Models were adjusted for maternal age, BMI, parity, peak estradiol level, endometrial thickness, insemination protocol (IVF or ICSI), female etiologies (tubal factor, endometriosis), order of transfer (1 or $>1$ ), mode of delivery (vaginal or cesarean) and year of treatment

a Data were unavailable because no event was observed.

A significant modification on the association between blastocyst morphology and birthweight by day 3 fragmentation was also observed when interaction terms were included (Supplementary Table S4). The size of association between inner cell mass grading and birthweight appeared to be increased when the blastocysts were derived from fragmented embryos (Figure 1). Comparing birthweight for blastocysts with grade A ICM to those having grades of B and C, the size of association increased by 473.4 ( $95 \% \mathrm{Cl}$ : 124.04 to 822.76$)$ and -70.42 (95\% Cl: -630.44 to 489.59$)$ respectively in fragmented group than no-fragmented group. The association between blastocyst quality and birthweight was also modified by day 3 fragmentation (Supplementary Table S4).

\section{Discussion}

Main outcomes

Our data suggested that day 3 fragmentation was associated with higher birthweight, regardless cleavage stage embryos or blastocysts were transferred in fresh cycles. Moreover, the association between blastocyst morphology and birthweight might be modified by the presence of fragmentation on day 3 . In the frozen-thawed cycles, however, no association between embryo morphology and birthweight was detected. In addition, our data did not support the argument that transferring a poor-looking embryo may increase the risks of low birthweight $(3,4)$, as we observed no association between embryo quality and birthweight in either fresh or frozen-thawed transfer cycles.

Strengths and limitations

Comparing with previous studies(3-11), our study may have several strengths. First, it was one of the largest studies on this topic, including singletons following both fresh and frozen-thawed transfers. Second, the data were collected in a relatively short period, minimizing the potential confounding over time(18). Finally, we took the both cleavage stage and blastocyst into consideration, allowing a discussion on the interrelation between cleavage and blastocyst stage embryos.

Our study is also limited by methodological defects similar to previous studies, including subjectivity of embryo assessment and retrospective nature of the study. The most profound bias may lie in the fact that patients receive a poor-looking embryo only when they have no choice. Therefore, singletons following transfer of a poor-looking embryo may be more likely to be delivered by poor prognosis mothers.

Interpretation

Fragment of cleavage stage embryos has been defined as presence of anuclear, membrane-bound extracellular cytoplasmic structures and used as a marker for poor prognosis embryos. Embryo fragmentation has been associated with reduced blastocyst formation, decreased implantation and increased early abortion. However, its role on birthweight remained less known. Ebner et al. demonstrated that mean birthweight of singletons following transfer of embryos with no fragmentation, <25\% fragmentation and 25\%-50\% fragmentation was $3128 \mathrm{~g}, 3235 \mathrm{~g}$ and $3421 \mathrm{~g}$ respectively. Although this early study was limited by 
a small sample size and the authors concluded that birthweight did not correlate with embryo quality (19), the numeric trend may support an association between fragmentation and birthweight.

The pathogenesis and biological significance of fragmentation in cleavage stage embryos is not fully understood. A transmission electron microscopy study revealed that the most abundant organelles in the fragment were mitochondria (20). Determination of extracellular mitochondrial DNA content suggested that fragment may release mitochondrial into culture medium(21). These observations may suggest a reduction in mitochondrial number and/or a deficient in mitochondrial function in fragmented embryos. Alternation in mitochondrial function during early embryo stage may affect later development. Using a mouse model, Zander-Fox et al. showed that disrupting the mitochondrial oxidative phosphorylation process during the cleavage stage embryo culture might reduce the birthweight and impair metabolic phenotypes of offspring(22). In humans, mitochondrial DNA depletion was founded in both SGA and LGA neonates (23). Together with the existing evidence, the present study suggested further research warranted to investigate the putative links between early embryo morphology, mitochondrial dysfunction and later life development.

Among the studies investigating the association between embryo quality and birthweight, Zhang et al. suggested an association between poor blastocyst morphology and low birthweight (4), whereas Huang et al. demonstrated increased risks of low birth following transferring poor quality cleavage stage embryos (3) in the same population. The inconsistency between their conclusions and ours may lay in the subjectivity of embryo assessment and the differentiation of embryo selection criteria. However, the authors of these studies also reported a relatively high z-score and a LGA rate up to $37.5 \%$ in singletons from top-quality embryos. To the contrast, our data demonstrated a population with much lower z-scores and LGA rates, using the same reference population(17). It suggests a significant difference in populations may contribute to the heterogeneity of studies. On the other hand, the lack of association between embryo quality and birthweight observed in our study was supported by several other studies $(5-7,10)$.

A few studies associated specific morphological features, rather than overall embryo score, with singleton birthweight, and yielded conflicting results (9-11). Licciardi et al. reported that a higher inner cell mass grade was associated with greater birthweight but the grade of the TE did not relate to weight(9). Controversially, Bakkensen et al., reported a negative association between ICM grades and birthweight(10). In a more recent study, advanced grade of TE, rather than ICM, was associated with increased birthweight(11). A possible reason for the discrepancy was that limited choices for ICM and TE grades, in combination with subjectivity, may limit the discriminatory power of the grading system. The majority of blastocysts (60\%-70\%) transferred were graded with "B" for either TE or ICM. Misclassification of the intermediate grade " $\mathrm{B}$ " may skew the estimation for both the higher and lower grade. When a more quantitative grading method was introduced, Ebner et al. reported no association of birthweight with either TE or ICM (24). However, this study only included 99 live births and needs to be confirmed in larger cohorts.

The association between blastocyst morphology and development potential might also be affected by their cleavage stage origin. Recent studies suggested that developmental potential of blastocysts might be different according to their morphology features in cleavage stage, even though a similar blastocyst grade is given(12-14). In advanced blastocysts with good quality, degree of fragmentation on day 3 may have a negative impact on implantation potential (14). Observations of Hardy et al. have revealed an interrelation between fragmentation and blastocyst morphology. Embryos with minimal or moderate levels of fragmentation (5\%-25\%) in cleavage stage had a reduced the cell numbers of TE but maintained a steady cell number in ICM in the blastocyst stage. However, the levels of apoptosis in the ICM were high in blastocysts from embryos without fragment and were lower in blastocysts from fragmented embryos (25). Apoptosis in ICM may play a crucial role in eliminating defective cells and regulating cell numbers(26). Therefore, observations of Hardy et al. may suggest an imbalanced ICM/TE development and/or a dysregulation of ICM growth in blastocysts following fragmentation, even though the morphology is similar to a blastocyst from embryos without fragment. Dysregulation of ICM is postulated to be associated with fetal overgrowth in animals(27). A decreased ICM/TE ratio may indicate an imbalance in placental development and explain some of the features of the large calf syndrome(27). Echoing the early observations, our interaction analysis suggested that an association between lower number of ICM cells and large babies may also exist in humans, but only when fragmentation is present in cleavage stage.

Our study failed to associate any of the morphological features with birthweight in frozen-thawed cycles and data suggested a significant modification of frozen-thawed on our estimate. It was not the first time data suggest that technologies may modify the association between embryo morphology and neonatal outcomes. Liberman et al. showed that cell number on day 3 is positively associated with birth weight, but only without assisted hatching (8). The authors hypothesized that creating an artificial hole in the zona pellucida by assisted hatching may alter embryonic metabolism and affect subsequent development. Similarly, vitrification may lead to a wide range of alternations in cellular structure, including the damage on mitochondria and cytoskeleton (28, 29) and has been associated with alternated neonatal outcomes. The effects of fragmentation on birthweight might be overwhelmed by the changes made by vitrification.

\section{Conclusions}

In conclusion, our data suggested that fragmentation in cleavage stage is associated with increased birthweight following either cleavage or blastocyst stage transfers in fresh cycles, but not in frozen-thawed cycles. Transferring fragmented embryos appeared to be safe for offspring, as infants with increased birthweight may show positive long-term health, development and educational outcomes (30). However, concerns for LGA infant still remain, because the risks of adult-onset diseases may also increase in people born with extremely high birthweight (31).

\section{Declarations}

Ethics approval and consent to participate

Institutional Review Board approval of this retrospective study was obtained from the Ethical Committee of the Medical College Xiamen University on 21 December 2019. 
Consent for publication

Not applicable.

Availability of data and materials

Not applicable.

Conflict of interest

The authors declare that they have no competing interests.

Funding

This work was supported by the National Natural Science Foundation of China [grant number 22176159]; the Xiamen medical advantage subspecialty construction project [grant number 2018296] and the Special Fund for Clinical and Scientific Research of Chinese Medical Association [grant number 18010360765].

Authors' contributions

J.C., L.L and J.R. contribute to conception and design. J.C., Z.L., W.W. and X.J. contribute to acquisition of data. J.C. and L.L. contribute to analysis and interpretation of data. All authors contribute to drafting the article or revising it critically for important intellectual content. All authors read and approved the final manuscript.

Acknowledgements

We thank Xinli Wang for her assistance in data processing.

\section{References}

1. Gardner DK, Lane M, Stevens J, Schlenker T, Schoolcraft WB. Blastocyst score affects implantation and pregnancy outcome: towards a single blastocyst transfer. Fertil Steril. 2000;73(6):1155-8.

2. Alpha Scientists in Reproductive M, Embryology ESIGo. The Istanbul consensus workshop on embryo assessment: proceedings of an expert meeting. Hum Reprod. 2011;26(6):1270-83.

3. Huang J, Tao Y, Zhang J, Yang X, Wu J, Kuang Y, et al. Poor Embryo Quality Is Associated With A Higher Risk of Low Birthweight in Vitrified-Warmed Single Embryo Transfer Cycles. Front Physiol. 2020;11:415.

4. Zhang J, Huang J, Liu H, Wang B, Yang X, Shen X, et al. The impact of embryo quality on singleton birthweight in vitrified-thawed single blastocyst transfer cycles. Hum Reprod. 2020;35(2):308-16.

5. Oron G, Son WY, Buckett W, Tulandi T, Holzer H. The association between embryo quality and perinatal outcome of singletons born after single embryo transfers: a pilot study. Hum Reprod. 2014;29(7):1444-51.

6. Zhu J, Lian Y, Li M, Chen L, Liu P, Qiao J. Does IVF cleavage stage embryo quality affect pregnancy complications and neonatal outcomes in singleton gestations after double embryo transfers? J Assist Reprod Genet. 2014;31(12):1635-41.

7. Bouillon C, Celton N, Kassem S, Frapsauce C, Guerif F. Obstetric and perinatal outcomes of singletons after single blastocyst transfer: is there any difference according to blastocyst morphology? Reprod Biomed Online. 2017;35(2):197-207.

8. Lieberman E, Ginsburg ES, Racowsky C. Rate of cell division and weight of neonates following IVF. Reprod Biomed Online. 2006;12(3):315-21.

9. Licciardi F, McCaffrey C, Oh C, Schmidt-Sarosi C, McCulloh DH. Birth weight is associated with inner cell mass grade of blastocysts. Fertil Steril. 2015;103(2):382-7 e2.

10. Bakkensen JB, Brady P, Carusi D, Romanski P, Thomas AM, Racowsky C. Association between blastocyst morphology and pregnancy and perinatal outcomes following fresh and cryopreserved embryo transfer. J Assist Reprod Genet. 2019;36(11):2315-24.

11. Xie Q, Du T, Zhao M, Gao C, Lyu Q, Suo L, et al. Advanced trophectoderm quality increases the risk of a large for gestational age baby in single frozenthawed blastocyst transfer cycles. Hum Reprod. 2021.

12. Zhao H, Liu H, Li M, Wu K. Clinical outcomes following frozen-thawed blastocyst transfers with blastocysts derived from different cell numbers on day 3 : a retrospective cohort study. J Assist Reprod Genet. 2020;37(3):641-8.

13. Wu J, Zhang J, Kuang Y, Chen Q, Wang Y. The effect of Day 3 cell number on pregnancy outcomes in vitrified-thawed single blastocyst transfer cycles. Hum Reprod. 2020;35(11):2478-87. 
14. della Ragione T, Verheyen G, Papanikolaou EG, Van Landuyt L, Devroey P, Van Steirteghem A. Developmental stage on day-5 and fragmentation rate on day-3 can influence the implantation potential of top-quality blastocysts in IVF cycles with single embryo transfer. Reprod Biol Endocrino. $2007 ; 5: 2$.

15. Skiadas CC, Jackson KV, Racowsky C. Early compaction on day 3 may be associated with increased implantation potential. Fertil Steril. 2006;86(5):138691.

16. Cai J, Liu L, Zhang J, Qiu H, Jiang X, Li P, et al. Low body mass index compromises live birth rate in fresh transfer in vitro fertilization cycles: a retrospective study in a Chinese population. Fertil Steril. 2017;107(2):422-9 e2.

17. Dai L, Deng C, Li Y, Zhu J, Mu Y, Deng Y, et al. Birth weight reference percentiles for Chinese. PloS one. 2014;9(8):e104779.

18. Castillo CM, Horne G, Fitzgerald CT, Johnstone ED, Brison DR, Roberts SA. The impact of IVF on birthweight from 1991 to 2015 : a cross-sectional study. Hum Reprod. 2019;34(5):920-31.

19. Ebner T, Yaman C, Moser M, Sommergruber M, Polz W, Tews G. Embryo fragmentation in vitro and its impact on treatment and pregnancy outcome. Fertil Steril. 2001;76(2):281-5.

20. Halvaei I, Khalili MA, Esfandiari N, Safari S, Talebi AR, Miglietta S, et al. Ultrastructure of cytoplasmic fragments in human cleavage stage embryos. J Assist Reprod Genet. 2016;33(12):1677-84.

21. Stigliani S, Anserini P, Venturini PL, Scaruffi P. Mitochondrial DNA content in embryo culture medium is significantly associated with human embryo fragmentation. Hum Reprod. 2013;28(10):2652-60.

22. Zander-Fox DL, Fullston T, McPherson NO, Sandeman L, Kang WX, Good SB, et al. Reduction of Mitochondrial Function by FCCP During Mouse Cleavage Stage Embryo Culture Reduces Birth Weight and Impairs the Metabolic Health of Offspring. Biol Reprod. 2015;92(5):124.

23. Gemma C, Sookoian S, Alvarinas J, Garcia SI, Quintana L, Kanevsky D, et al. Mitochondrial DNA depletion in small- and large-for-gestational-age newborns. Obesity. 2006;14(12):2193-9.

24. Ebner T, Tritscher K, Mayer RB, Oppelt P, Duba HC, Maurer M, et al. Quantitative and qualitative trophectoderm grading allows for prediction of live birth and gender. J Assist Reprod Genet. 2016;33(1):49-57.

25. Hardy K, Stark J, Winston RM. Maintenance of the inner cell mass in human blastocysts from fragmented embryos. Biol Reprod. 2003;68(4):1165-9.

26. Pisko J, Spirkova A, Cikos S, Olexikova L, Kovarikova V, Sefcikova Z, et al. Apoptotic cells in mouse blastocysts are eliminated by neighbouring blastomeres. Sci Rep. 2021;11(1):9228.

27. Leese HJ, Donnay I, Thompson JG. Human assisted conception: a cautionary tale. Lessons from domestic animals. Hum Reprod. 1998;13 Suppl 4:184202.

28. Chatzimeletiou K, Morrison EE, Panagiotidis Y, Vanderzwalmen P, Prapas N, Prapas Y, et al. Cytoskeletal analysis of human blastocysts by confocal laser scanning microscopy following vitrification. Hum Reprod. 2012;27(1):106-13.

29. Gao Z, Yao G, Zhang H, Liu H, Yang Z, Liu C, et al. Resveratrol protects the mitochondria from vitrification injury in mouse 2-cell embryos. Cryobiology. 2020;95:123-9.

30. Zeng P, Zhou X. Causal Association Between Birth Weight and Adult Diseases: Evidence From a Mendelian Randomization Analysis. Front Genet. 2019;10:618.

31. Knop MR, Geng TT, Gorny AW, Ding R, Li C, Ley SH, et al. Birth Weight and Risk of Type 2 Diabetes Mellitus, Cardiovascular Disease, and Hypertension in Adults: A Meta-Analysis of 7646267 Participants From 135 Studies. J Am Heart Assoc. 2018;7(23):e008870.

\section{Figures}

\section{Image not available with this version}


Figure 1

Modification of day 3 fragmentation on the association between blastocyst morphology and z-score. (A-B) Adjusted regression coefficient ( $95 \%$ Cl) of ICM for z-score in fresh (A) and frozen (B) cycles. (C-D) Adjusted regression coefficient (95\% Cl) of TE for z-score in fresh (C) and frozen (D) cycles. (E-F) Adjusted regression coefficient $(95 \% \mathrm{Cl})$ of embryo quality for z-score in fresh $(E)$ and frozen $(F)$ cycles. Models were adjusted for maternal age, BMI, parity, peak estradiol level, endometrial thickness, insemination protocol (IVF or ICSI), female etiologies (tubal factor, endometriosis), order of transfer (1 or $>1$ ), mode of delivery (vaginal or cesarean) and year of treatment.

\section{Supplementary Files}

This is a list of supplementary files associated with this preprint. Click to download.

- Figures1.tif

- Figures2.tif

- Tables1.docx

- Tables2.docx

- Tables3.docx

- Tables4.docx 